\title{
Armchair Access and Imagination
}

\author{
Giada Fratantonio \\ University of Helsinki \\ Forthcoming in Dialectica
}

[This is a pre-copy-edited version. Please cite published version when possible.]

\begin{abstract}
In this paper, I focus on the Armchair Access Problem for $\mathrm{E}=\mathrm{K}$ as presented by Nicholas Silins (2005), and I argue, contra Silins, that it does not represent a real threat to $E=K$. More precisely, I put forward two lines of response, both of which put pressure on the main assumption of the argument, namely, the Armchair Access thesis. The first line of response focuses on its scope, while the second line of response focuses on its nature. The second line of response is the most interesting one, for it represents the framework within which I develop a novel account of second-order knowledge, one that involves evaluation of counterfactual conditionals and the employment of our imaginative capacities, i.e., an imagination-based account of second-order knowledge. The two lines of response are shown to be jointly compatible and mutually supportive. I then conclude that the Armchair Access Problem is not a challenge for $\mathrm{E}=\mathrm{K}$, yet it relies on the ambiguity of the notion of armchair knowledge underpinning the Armchair Access thesis.
\end{abstract}

\section{INTRODUCTION ${ }^{1}$}

There is little consensus, among philosophers, on what evidence is. Following Silins (2005), I will here cash out the disagreement over the notion of evidence as being represented by the opposition between Evidential Internalism and Evidential Externalism. While philosophers have dedicated lots of attention to the Internalism-Externalism debate

\footnotetext{
${ }^{1}$ I would like to thank Aidan McGlynn, Duncan Pritchard, Lukas Schwengerer, and Martin Smith for reading and commenting on different versions of this paper, and for extremely useful discussions on this topic. I have presented part of this paper at the XXV SIUCC SEFA's Workshop on Timothy Williamson at University of Valencia, and at the Italian Society for Analytic Pbilosophy 2016. I would like to thank all those who attended those events and, in particular, Cameron Boult, Tommaso Piazza, and Timothy Williamson for useful feedback provided in those occasions. I would also like to thank Jaakko Hirvelä and Maria Lasonen-Aarnio, whose feedback helped me addressing some of the reviewer's concerns. Finally, I am grateful to an anonymous reviewer for very thorough and useful comments that have enabled me to improve this paper. This project has received funding from the European Research Council (ERC) under the European Union's Horizon 2020 research and innovation programme under grant agreement No 758539.
} 
over epistemic justification, the Internalism-Externalism debate over the notion of evidence is still widely overlooked.

Let internal twins share all non-factive mental states. According to Evidential Internalism, necessarily, if A and B are internal twins, then A and B have the same evidence. By contrast, Evidential Externalism allows internal twins to differ in what their evidence is. That is, according to Evidential Externalism, it is possible that: A and B are internal twins, and A and B do not have the same evidence (Silins, 2005: 376-77). ${ }^{2}$

In his 'Deception and Evidence', Silins claims that there is an argument showing that "Evidential Externalism is false because it has unacceptable consequences about what one knows from the armchair" (Silins, 2005: 380). More precisely, Silins' target is a specific variety of Evidential Externalism, namely, Timothy Williamson's $\mathrm{E}=\mathrm{K}$, which equates one's evidence to one's knowledge (Williamson, 2000). Following Silins, I will here focus on Williamson's $\mathrm{E}=\mathrm{K} .^{3,4}$

Silins' argument aims to show that, given a (allegedly) plausible thesis about what we can know from the armchair, $\mathrm{E}=\mathrm{K}$ leads to the unacceptable conclusion that we can have armchair knowledge of specific empirical propositions. Call this the Armchair Access Problem. In this paper, I argue that Silins' Armchair Access Problem does not represent a challenge for Williamson's $\mathrm{E}=\mathrm{K}$, for it relies on an account of armchair knowledge that Williamson should reject. First, I reconstruct Silins' argument (Section 1), and I shed light on the nature of its main assumption (Sections 2). Second, I develop two lines of response, both of which put pressure on Silins' Armchair Access thesis. While the first response focuses on the scope of the thesis (Section 3), the second response focuses on its nature (Section 4). The second line of response represents the framework within which I develop a novel account of second-order knowledge through imagination. After resisting a possible objection to my argument (Section 5), I point out that these two lines of response are mutually supportive and jointly compatible. I thus conclude that the Armchair Access Problem does not represent a threat for Williamson's variety of Evidential Externalism, i.e., $\mathrm{E}=\mathrm{K}$ (Section 6).

\footnotetext{
${ }^{2}$ Henceforth, when I refer to Externalism, I have in mind what here I call, following Silins, Evidential Externalism, rather than more traditional varieties of externalism about epistemic justification, e.g., process reliabilism. For an overview of the main arguments and motivations behind Evidential Internalism and Evidential Externalism see Fratantonio (forthcoming).

${ }^{3}$ Notoriously, Epistemological Disjunctivism, formulated in terms of evidence, is subjected to a similar Access Problem. See Pritchard (2012: 46).

${ }^{4}$ In his Deception and Evidence, Silins develops two more arguments against E=K, i.e., the so-called "Supervenience Argument", and a novel skeptical argument. See Fratantonio and McGlynn (2018) for a response to those arguments.
} 


\section{THE ARMCHAIR ACCESS PROBLEM}

The variety of access argument that represents the focus of my paper is one which does not rest on the following Luminosity thesis:

[Luminosity]: For any proposition P, if one is suitably alert and conceptually sophisticated, then one is in a position to know whether or not one's evidence includes P. (Silins, 2005: 380)

The access problem I will address here is one that arises even if we accept Williamson's thesis that whether $\mathrm{p}$ is part of one's evidence is not a luminous condition. That is, even if we grant that it is not the case that if $\mathrm{E}$ is part of one's evidence, then one is always in a position to know that $\mathrm{E}$ is part of one's evidence. Silins is well aware of Williamson's antiluminosity argument. ${ }^{5}$ In fact, he explicitly takes his Armchair Access Problem to be a "novel access argument which uses a very different thesis, one which is not touched by Williamson's argument against [luminosity]" (Silins, 2005: 380). As Silins points out, while the luminosity thesis represents a very strong claim about what one can have access to, this novel argument relies, as we will see shortly, on a weaker and more plausible claim, one which is compatible with the limited nature of one's knowledge of one's evidence. Let us now see how the argument goes.

Let us imagine an agent, Gary, who is in a room staring at a dial. Gary sees that the dial reads 0.4. Let us assume Gary is in a perceptually good case ${ }^{6}$. By seeing that the dial reads 0.4, he thereby comes to know that the dial reads 0.4. Crucially, if $\mathrm{E}=\mathrm{K}$ is true, then the proposition that the dial reads 0.4 belongs to Gary's evidence. Let us now assume that Gary considers what evidence he has. The Armchair Access Problem against E=K runs schematically - as follows:

\footnotetext{
5 The target of Williamson's anti-luminosity argument, as presented in Knowledge and Its Limits, is all nontrivial conditions, where a condition is trivial when either it always obtains, or it never does. However, I will here narrow my focus on the non-trivial conditions concerning knowledge and evidence.

${ }^{6} \mathrm{I}$ take a perceptually good case to be a paradigmatic good case in which the subject $\mathrm{S}$ has a veridical experience, her perceptual capacities are reliable and fully functioning, no luck is involved, etc. That is, one in which S obtains perceptual knowledge.
} 
(1) Gary has armchair knowledge that his evidence includes the proposition that the dial reads 0.4 .

(2) Gary has armchair knowledge that, if his evidence includes the proposition that the dial reads 0.4 , then the dial reads 0.4 .

So,

(3) Gary is in a position to have armchair knowledge that the dial reads 0.4 (Silins, 2005: 382).

The foregoing argument is grounded on the following thesis about what we can know from the armchair:

(Armchair Access): It is sometimes the case that: one's evidence includes some proposition E, and one knows from the armchair that one's evidence includes E.

(Silins, 381-2)

In a nutshell, Silins' argument is that, given that it is sometimes possible to know, merely from the armchair, that a proposition $\mathrm{p}$ is part of our evidence, then, given factivity of evidence and a plausible closure principle for armchair knowledge, we can competently deduce, and thereby know, what this propositional evidence entails. Given $E=K$, if $p$ is part of my evidence, then I know that $\mathrm{p}$. Therefore, assuming factivity of knowledge, if $\mathrm{p}$ is part of my evidence, then $\mathrm{p}$ is true. It follows that if I can know from the armchair that a proposition $\mathrm{p}$ is part of my evidence, then I can competently deduce, thereby coming to know merely from the armchair, that $\mathrm{p}$ is true. ${ }^{7}$ But, Silins says, although "Gary can know what the dial reads, he cannot know such a proposition through armchair reflection" (Silins, 2005: 382). It's worth noticing that Silins develops this argument as a parallel to the more notorious McKinsey Paradox, concerning the incompatibility between Privileged Access and Semantic Externalism (McKinsey, 1991). Privileged Access is, roughly put, the

\footnotetext{
${ }^{7}$ Note that not only is the factivity of evidence easily derived from $\mathrm{E}=\mathrm{K}$ and factivity of knowledge, yet a priori philosophical arguments have also been provided in favor of the fact that if $\mathrm{p}$ is part of your evidence then p is true. (see Littlejohn, 2012: ch. 3)
} 
thesis that one can typically know by reflection the content of one's mental states. Content Externalism is, roughly put, the thesis that the content of one's mental states is determined by factors in the external environment. Imagine that one is thinking that the water is wet. Privileged Access entails that one can know by reflection that one is thinking that water is wet. Content Externalism entails that if one has a thought about water, then one must have had interacted with $\mathrm{H} 2 \mathrm{O}$. Assuming one can know by reflection that Content Externalism and Privileged Access are true, and assuming a closure principle for reflective knowledge, the McKinsey Paradox aims to show that one can know by reflection a contingent fact about the external environment (one can know by reflection that one has interacted with H20), yet this is absurd.

In what follows, I argue that Silins' argument does not undermine Williamson's E=K. In order to do so, first, I evaluate and shed light on Silins' notion of armchair knowledge as underlying the Armchair Access thesis. Second, I argue that Gary's knowledge of his evidence does not constitute an instance of armchair knowledge as defined by Silins.

\section{WHAT IS ARMCHAIR KNOWLEDGE?}

\subsection{ON SILINS’ NOTION OF ARMCHAIR KNOLWEDGE}

To fully understand Silins' Armchair Access Problem, we need to clarify the notion of armchair knowledge he employs.

To begin with, I would like to point out that Silins' introduction of the first premise is too abrupt. Silins introduces the argument by stating that "Gary has armchair knowledge that his evidence includes the proposition that the dial reads 0.4" (Silins, 2005: 382). Crucially, given $\mathrm{E}=\mathrm{K}$, to know what propositions belongs to one's evidence is, first of all, to know what one's knowledge is. That is, given $\mathrm{E}=\mathrm{K}$, knowledge of one's evidence is nothing more than knowledge of one's knowledge. If we then ask what is the nature of Gary's knowledge that the dial reads 0.4 , the answer will be straightforward. Gary's firstorder knowledge is an instance of perceptual knowledge. Gary sees that the dial reads 0.4, thereby coming to know that the dial reads 0.4 . But if we ask what is the nature of Gary's knowledge that he knows, the answer seems to be less straightforward. The following worry arises: is Gary's knowledge of his evidence, and thus Gary's knowledge of his knowledge, an instance of armchair knowledge, as stated in premise (1)? 
In order to answer this question, it is worthwhile to shed light on what it means, according to Silins' formulation, to have armchair knowledge of a proposition. Silins defines armchair knowledge as follows:

"One has armchair knowledge of a proposition when one knows it, and one's justification for believing the proposition does not constitutively depend on one's having had any particular experience or sense experience" (Silins, 2005: 380)

The foregoing definition is of little help unless we get a clear idea of what the notion of constitutive dependency amounts to. According to Silins:

“[...] one can have armchair knowledge of a proposition, even if a background condition for having that knowledge is that one has had a certain experience or type of experience. For example, one might have armchair knowledge that redness is a colour, even if one knows that proposition only if one has had experiences of redness" (Silins, 2005: 381)

In order to have a better understanding of what notion of armchair knowledge Silins has in mind, let us consider the distinction, often used in the a priori/a posteriori debate, between the enabling role of experience and the evidential role of experience. The enabling role of experience is usually taken to be what enables us to understand the concepts involved in the target proposition. The latter form of experience is what is sometimes required, besides the enabling experience, in order for one to know a proposition. As Williamson says: "[e]xperience is held to play an evidential role in our perceptual knowledge that it is sunny, but a merely enabling role in our knowledge that if it is sunny then it is sunny: we needed it only to acquire the concept sunny in the first place" (Williamson, 2013: 293).

Silins' words in the above-mentioned quotation seem to suggest that, even if there is a sense in which one requires a certain experience (e.g., having perceived redness, having interacted with a linguistic community) in order to know a proposition (redness is a colour), this instance of propositional knowledge should be considered as being armchair knowledge as long as the required experience is merely enabling one to understand the concept involved (redness). If what Silins has in mind is that armchair knowledge is compatible with having had enabling experience, then to say that armchair knowledge does 
not constitutively depend on experience is to say that it does not depend on evidentialjustificatory experience. That is, Silins seems to take armchair knowledge to be based on enabling experience only. ${ }^{8}$ If it is possible to have such armchair knowledge, then, according to Silins, we should expect Gary's knowledge of his evidence to be a perfect candidate for armchair knowledge: "we should expect that Gary knows from the armchair that his evidence includes the proposition that the dial reads 0.4" (Silins, 2005: 381).

As mentioned above, Slins is well aware of Williamson's anti-luminosity argument. However, even if we are not always in a position to know from the armchair what our evidence (and thus our knowledge) is, it is plausible to claim that we are sometimes able to know from the armchair what knowledge and what evidence we have. Given that Armchair Access is compatible with the limits of our knowledge, then everyone - including Williamson - would probably be on board with that. In what follows, I argue that Silins's argument does not represent a challenge to Williamson's $\mathrm{E}=\mathrm{K}$, insofar as it relies on a very questionable notion of armchair knowledge. More precisely, I will put forward two lines of response to Silins' argument. On the first line of response, I argue that, given Silins' formulation of Armchair Access, there is a plausible restriction the externalist would build into Armchair Access thesis, one that prevents the argument from getting going. On the second line of response, I argue that, even if we grant that there is a sense in which Williamson should acknowledge the possibility of one's having knowledge "from the armchair" of one's evidence, this knowledge is not a problematic instance of armchair knowledge as understood by Silins. In order to do so, I take Williamson's cognitive-based account of imagination as a framework for understanding what's happening in Gary's scenario, thereby suggesting an imagination-based account of second-order knowledge. As I will show in the conclusion of this paper, these two lines of response are compatible and mutually supportive.

\subsection{A CLARIFICATION}

Before developing my responses, a clarification is in order. One can point out that there is a straightforward way of resisting the Armchair Access Problem. That is, one could

\footnotetext{
${ }^{8}$ Although Silins does not explicitly use this terminology, the text I've quoted seems to suggest, as I've just pointed out, that he has this distinction in mind. Note also that the notion of Privileged Access in McKinsey and in the McKinsey literature is stated as "a priori" knowledge, where this includes introspection. By contrast, in the a priori/a posteriori debate, introspection is generally not taken to be a priori knowledge. See Nuccetelli (1999), Brown (2004), and Farkas (2008) for relevant discussion.
} 
argue that the conclusion (3) does not follow from the premises: Gary does not know from the armchair that the dial reads $0.4{ }^{9}$ The reason is simply that Gary already knew that the dial reads 0.4 by looking at the dial (by assumption). The Armchair Access Problem would thus not be a genuine problem, as Gary has an empirical basis for believing that the dial reads $0.4^{10}$. However, I believe this is not an effective response for at least two reasons. First, note that the validity of the Armchair Access Problem as presented by Silins, depends on the truth of a plausible closure principle for armchair knowledge. Anyone who resists the argument by claiming that the conclusion (3) fails to follow from the premises (1) and (2), thus also has to reject closure for armchair knowledge, while providing a satisfying explanation of why Gary's empirical basis in (1) prevents the entailment from (1) to (3). Second, I believe this reply fails to capture the real worry underpinning the Armchair Access Problem.

Everyone - including Silins - would grant that Gary originally had empirical knowledge of the target proposition. However, it still seems problematic to claim that he can reach knowledge of the same empirical proposition from the armchair. As Silins says:

"[I] know that I am having a certain sense experience only if I am having the sense experience, but that does not show that I lack armchair knowledge that I am having the experience. The source of my knowledge is arguably still reflection instead of experience" (Silins, 2005: 381) ${ }^{11}$

Analogously to the original McKinsey challenge, I believe we can appreciate the (prima facie) problematic nature of the Armchair Access Problem once we state it as a paradox. We start from a very plausible claim about what we can know from the armchair (the Armchair Access thesis), and from a plausible distinction between enabling and evidential experience, and we reach a very counterintuitive conclusion, namely, that we can gain knowledge of empirical propositions that is grounded on enabling experience only. Even if

\footnotetext{
9 Thanks to Cameron Boult and Tommaso Piazza for raising this objection to me in conversation.

10 Pritchard (2012) provides a similar response as a solution to an analogous access problem that seems to threaten his epistemological disjunctivism. Whether Pritchard's response is successful or not is a topic for another discussion.

${ }^{11}$ Note that someone could further point out that what Silins is saying here is not even possible. That is, one could object that, in order for the source of one's knowledge to be reflection instead of experience, one's belief in the target proposition must be completely based on the non-empirical reasoning only, rather than on sense experience. However, I will not develop this line of response here.
} 
one could (rightly) highlight Gary's original empirical knowledge, I still believe that we need to say something more in order to account for the above-mentioned paradox. What follows should thus be conceived in the light of the paradoxical structure under which the Armchair Access Problem can be presented. More importantly, the rest of the paper should be understood in the light of the following question: what is the role experience plays in so-called armchair knowledge?

\section{A FIRST RESPONSE:}

\section{A RESTRICTION OF ARMCHAIR ACCESS}

As seen in the previous sections, Silins' argument relies on the following thesis regarding our access to our evidence:

(Armchair Access): It is sometimes the case that: one's evidence includes some proposition E, and one knows from the armchair that one's evidence includes E. (Silins 2005: 381)

I have also already mentioned that Silins takes Armchair Access to be overwhelmingly plausible as well as compatible with Williamson's anti-luminosity argument. We can ask: is there a restriction that Williamson, and the externalist more generally, could plausibly build into Armchair Access as defined by Silins? Presumably, the externalist would restrict Armchair Access to non-environmentally sensitive propositions, thereby saying that we can have armchair knowledge of some instances of our evidence, but not of all of them. ${ }^{12}$ Silins takes this to be an ad hoc move, something the Externalist is forced to do merely in order to resist the challenge. However, it is unclear why this move would be ad hoc. In fact, there are reasons to think the opposite is true. First, remember that 'armchair knowledge' as conceived by Silins is knowledge based on enabling experience only. But if this is the notion of armchair knowledge Silins has in mind, then claiming that we can have enabling-based knowledge of some evidence only is thus a very plausible move regardless of whether it resists the Access Problem or not, a move that, in fact, might also

\footnotetext{
${ }^{12}$ I take environmentally sensitive propositions to be propositions whose truth-value depend on how the environment is. By contrast, I take non-environmentally sensitive propositions to be propositions whose truth-value does not depend on how the environment is.
} 
be made in the context of the a priori/a posteriori debate. Second, note that, by drawing a parallel with the McKinsey Paradox, Silins has formulated Armchair Access as a rather weak existential claim (i.e., Armchair Access is introduced by: "it is sometimes the case that'), and this is exactly what makes both McKinsey's and Silins' access theses look quite plausible. ${ }^{13}$ Silins' concern about the restriction being ad hoc would thus be weighty only if he were committed to an access thesis that has the strength of a universal claim. Finally, note that Silins himself points out that, unlike the more notorious Luminosity Argument, his novel access argument rests on a weaker access thesis, thereby focusing on how one can know one's evidence, rather than putting pressure on when one can know one's evidence (Silins, 2005: 380). ${ }^{14}$

But, if we restrict Armchair Access to non-environmentally sensitive propositions, what are we left with? I take mathematical and logical truths to be a plausible candidate. It might be an open question whether visual thinking, as well as the use of external representations (e.g., symbols, arrows, diagrams, computer simulations, graphs) should seriously cast doubts on the a priori nature of mathematical knowledge. Nevertheless, the standard view has it that knowledge of mathematical truths generally depends on enabling experience only. This is highly uncontroversial. However, if this is the case, then Williamson, and the Externalist more generally, could thus restrict Armchair Access to nonenvironmentally sensitive propositions, without leaving Armchair Access an unmotivated and empty claim. ${ }^{15,16}$

\footnotetext{
${ }^{13}$ In fact, as mentioned above, McKinsey's Privileged Access is the thesis that typically one is in the position to know by reflection the content of one's mental states.

${ }^{14}$ In Fratantonio and McGlynn (2018: 86-90), we suggest a similar, yet less developed, response.

${ }^{15}$ Note that it is not entirely appropriate to talk about a "restriction" of Armchair Access. As I mentioned above, Armchair Access is formulated as an existential claim. This is what makes it very plausible. What I am doing here is to pick some propositions as instances of that existential claim. However, given Silins himself calls this sort of move to be a "restriction" of Armchair Access, I here use his terminology.

${ }^{16}$ Although I believe it is very plausible to assume that mathematical and logical knowledge can be evidence for something, one might instead find this idea questionable. In particular, one could point out that, given Williamson's account of the "evidence-for" relation, one on which e is evidence for $\mathrm{p}$ iff e increases the probability of p, mathematical knowledge can never work as evidence for a hypothesis (cf. Williamson, 2000, ch.9 and 10). This is because, roughly put, the probability of a mathematical truth is always 1 (by the axioms of probability). However, I don't think this is a problem for the purpose of this argument. In particular, note that, while this problem is the result of understanding the evidential-support relation in probabilistic terms, $\mathrm{E}=\mathrm{K}$ is a mere claim about the nature of evidence, and it does not by itself entail anything about what it takes for a proposition e to be evidence for $\mathrm{p}$. Furthermore, note that if porbabilism about evidential-support is true, then nothing can be evidence for mathematical truths. This seems a problematic result and yet this does not depend on assuming that mathematical truths can be part of one's evidence. This shows, once again, that what is problematic is probabilism about evidential-support, rather than $\mathrm{E}=\mathrm{K}$. The defender of $\mathrm{E}=\mathrm{K}$ has thus two options here. Either she could say that mathematical knowledge does indeed belong to our "box of evidence", although it cannot support any proposition (cf. Logins 2016 for a relevant discussion on whether this strategy could work). Or, she could embrace an alternative account of evidential support, e.g.,
} 
Once we realise that a plausible restriction of Armchair Access thesis to nonenvironmentally sensitive propositions is available, the argument does not go through: given Silins' notion of armchair knowledge, the Externalist would be happy to deny that Gary has armchair knowledge of the fact that his evidence includes the proposition that the dial reads 0.4. If Silins wants to show that $\mathrm{E}=\mathrm{K}$, when joined with Armchair Access, brings about the undesirable conclusion, he has to consider a different example, one which the Externalist would be happy to grant as a case of armchair knowledge as defined by Silins, namely, as a case of knowledge based on enabling experience only.

\section{A SECOND RESPONSE:}

\section{ON THE NATURE OF ARMCHAIR KNOWLEDGE}

In the previous section, I have argued that Silins is too dismissive in taking any restriction of Armchair Access to be ad hoc. The conclusion of my first line of response was thus that it is far from clear why Williamson should accept the first premise of Silins' argument:

1) Gary has armchair knowledge that his evidence includes the proposition that the dial reads 0.4 .

However, someone might not find this first line of response as intellectually satisfying as it should be. For one could still object that it is plausible to say that there is a sense in which we can sometimes know "from the armchair" what our evidence is, even when our evidence includes a proposition about the environment. After all, even Williamson explicitly allows for extended but not unlimited knowledge of our knowledge, as well as of our evidence. For instance, Williamson himself grants the possibility of knowledge of our evidence when he writes:

a normic account (cf. Smith 2016), or an Explanationist account (cf. McCain 2012). Thanks to an anonymous referee for pointing out this potential worry to me. 
"Our extensive but not unlimited ability to know that we know without further observation whether we know something is what enables us to use knowledge as evidence. It constitutes an extensive but not unlimited ability to know without further acquisition of evidence whether something is part of our present evidence." (Williamson, 2000: 15)

Similarly, Williamson acknowledges that, although no non-trivial mental state is luminous, "none of this is to deny that in favourable cases one can know without observation whether one is in a given mental state" (Williamson, 2000: 14). It might thus be tempting to argue that there is a sense in which even Williamson has to grant Gary knowledge of what his evidence is. Nonetheless, as I will show in the second half of this paper, I believe that we should be careful in assimilating what Williamson takes to be "knowledge without further observation" with Silins' notion of armchair knowledge.

In what follows, I put forward a second line of response against Silins' argument. I argue that, although we do need to account for the fact that it is sometimes possible to know what our evidence is merely "from the armchair", Silins' argument relies on a notion of armchair knowledge that Williamson should reject. That is, I argue that Gary's knowledge of his evidence (and, given $\mathrm{E}=\mathrm{K}$, Gary's knowledge of his knowledge) is not an instance of armchair knowledge as understood by Silins, namely, it is not an instance of knowledge depending on enabling experience only. This will enable us to resist the Armchair Access Problem. For reasons of simplicity, instead of directly addressing Gary's knowledge of his evidence, I will consider Gary's second-order knowledge. This is because $\mathrm{E}=\mathrm{K}$ allows me to apply the conclusions I draw on the nature of one's second-order knowledge to cases of one's knowledge of one's evidence.

The main challenge taken up in this paper is to provide a plausible explanation of why, in cases of higher-order knowledge where one's first-order knowledge is empirical, I consider second-order knowledge to not be armchair knowledge in any problematic sense. ${ }^{17}$ I will not defend any specific theory of second-order knowledge, for an evaluation of which account is the correct one is beyond the scope of this paper. However, for the purpose of this paper, I will consider cases in which a subject has second-order knowledge in virtue of: i) having first-order knowledge (assuming factivity of knowledge), and ii)

\footnotetext{
${ }^{17}$ Note that, in this paper, I am only concerned with cases of second-order knowledge (or higher-order knowledge). That is, I am interested in a person's knowledge of her knowledge, and not in her (psychological) self-knowledge, understood more broadly as the person's knowledge of her own mental states.
} 
having conducted a further inquiry on her epistemic status (more precisely, on her firstorder knowledge). This further inquiry must not be empirical, and it must, of course be properly conducted in order to constitute knowledge. It's important to stress that I do not want to suggest that second-order knowledge can only be achieved by means of a further inquiry on one's epistemic status. In fact, it is plausible to think that, in some cases, one might be able to easily achieve second-order knowledge merely by being exposed to first order knowledge. ${ }^{18}$ In Section 5, I will address more explicitly these cases of 'easy secondorder knowledge', and I will argue they do not constitute a threat to my overall strategy. However, my focus here will be mainly on cases of second-order knowledge that involve reflection on one's epistemic status, for this represents Silins' target as well. In particular, his being concerned with these 'reflective' cases of second-order knowledge is clear when he describes the Gary scenario. He says:

"[W] can focus on a thoughtful subject in the good case. Suppose Gary sees that the dial reads 0.4 , and considers what evidence he has and what his having certain evidence entails." (Silins, 2005: 381. Italics are mine).

In the Gary scenario, Gary knows that $\mathrm{p}$ by having a paradigmatic visual experience that p. Given what I have said above, if Gary knows that he knows that p, then Gary knows that $\mathrm{p}$ and Gary has conducted a further inquiry on his epistemic status, namely, on whether he indeed had a paradigmatic knowledge-yielding visual experience that $\mathrm{p}$. What follows can thus be understood as indicating a way of cashing out what this 'further inquiry' involves. In particular, I shall address two questions. First, what is the object of this inquiry? Second, what is the nature of this inquiry?

Before providing an answer to these questions, I will consider Williamson's imagination-based epistemology of counterfactuals and how, on Williamson's view, the employment of these imaginative capacities involves experience playing a role which is "more than merely enabling and less than strictly evidential" (Williamson, 2016). I will then go back to address the questions regarding the object and the nature of Gary's further inquiry on his first-order knowledge. By developing a new application of Williamson's

\footnotetext{
18 Thanks an anonymous referee for addressing this concern, and to Timothy Williamson for raising a similar point to me in conversation.
} 
cognitive-based account of imagination, namely, an imagination-based account of secondorder knowledge, I will argue that we should understand Gary's further inquiry on his epistemic status as involving those imaginative capacities that Williamson takes to be in place when we evaluate counterfactuals, or when we come to know some propositions, allegedly taken to be known a priori. I will conclude that, if my imagination-based account of second-order knowledge is correct, then there are good reasons to believe Williamson would resist the major assumption of Silins' argument: Gary's knowledge of his evidence is not "armchair" in any problematic sense, namely, it is not based on enabling experience only. A general point can be made: once we consider seriously Williamson's stand on the a priori/a posteriori distinction, Silins' objection can be undermined. Even if there is a sense in which our second-order knowledge is "armchair", namely, it is not merely grounded on evidential experience, it is not, however, an instance of armchair knowledge as underlying Silins' interpretation of the Armchair Access thesis. That is, our second-order knowledge is not grounded on enabling experience only.

Recently Williamson has offered an imagination-based account of epistemology of counterfactuals. ${ }^{19}$ That is, he argues that in evaluating a counterfactual conditional, namely, in considering both its antecedent and its consequent, we employ our imaginative cognitive capacities. ${ }^{20}$ In order to understand what Williamson has in mind, let us consider his own example as introduced in The Philosophy of Philosophy:

You are in the mountains. As the sun melts the ice, rocks embedded in it are loosened and crash down the slope. You notice one rock slide into a bush. You wonder where it would have ended if the bush had not been there. A natural way

\footnotetext{
19 See Williamson, 2007. It is worth pointing out that Williamson's imagination-based epistemology of counterfactuals should be understood within Williamson's aim of showing epistemology of metaphysical modalities as being a subset of the epistemology of counterfactuals. An evaluation of Williamson's epistemology of metaphysical modality is beyond the scope of this paper. For criticisms, see Jenkins, C. S. I, (2008).

${ }^{20}$ It's worth stressing that the notion of imagination here is not restricted to the Aristotelian notion of imagination as phantasia that might feature in dreaming and daydreaming (De Anima iii 3). Rather the notion of imagination at stake here is that of a broad capacity that shows itself in heterogeneity of knowledgeyielding cognitive processes, e.g., entertaining possibilities and alternative scenarios, evaluating counterfactuals, and making mental comparisons (cf. Williamson 2016).
} 
to answer this question is by visualizing the rock sliding without the bush there, and then bouncing down the slope into the lake at the bottom. Under suitable background conditions, you thereby come to know this counterfactual:

[...] if the bush had not been there, the rock would have ended in the lake. (Williamson 2007a: 142; Italics added)

What underpins Williamson's evaluation of the foregoing scenario is the idea that imaginative exercises are knowledge-yielding cognitive processes that involve "a general human capacity to transpose 'online' cognitive skills originally developed in perception into corresponding 'offline' cognitive skills subsequently applied in imagination” (Williamson, 2013: 296). ${ }^{21,22}$ Without performing any kind of empirical experiment, one can come to know a counterfactual by "visually" imagining its antecedent in one's mind and by spontaneously developing its consequent. These two moments in the evaluation of a counterfactual mirror, on Williamson's view, the two moments involved in our imaginative exercise: a first one in which imagination is exercised voluntarily, and a second one in which it is employed involuntarily. The former modus operandi of imagination is exercised when we make ourselves imagine a possible scenario. That is, we voluntarily consider a specific possibility and we try to imagine what would happen if we were in that possible scenario. However, the imagination works involuntarily when it comes to fill the target possible scenario with details. In Williamson's words:

" $[\mathrm{H}]$ aving forced the initial conditions, [one] lets the rest of imaginative exercise unfold without further interference" (Williamson, 2016: 116)

But what enables one to "involuntarily" develop the consequent of a counterfactual in such a way that it produces knowledge? That is, what makes imagination a knowledge-yielding cognitive process? On Williamson's view, our imagination is always constrained by our

\footnotetext{
${ }^{21}$ Similar ideas can also be found in Williamson 2007, 2016.

22 Unfortunately, Williamson leaves the notion of "offline" rather unexplained in his texts. However, it is plausible to understand Williamson's use of the notion of "offline" to be similar to the notion used by defenders of simulation theory (e.g., Goldman, 1989). That is, the imagination is the result of "offline" cognitive skills insofar as, roughly put, these cognitive skills work with surrogated and idealised situations and they can be employed in the absence of the actual object/scenario imagined. This also involves the idea that one can update one's belief even in the absence of the new evidence. See Williamson, 2007, 2016.
} 
background knowledge, where this includes our past experiences. More precisely, our past experiences determine the operation of imagination in at least two ways. ${ }^{23}$ First, when addressing the imagined scenario, our 'offline' cognitive skills minimise the changes with respect to our background knowledge of similar cases. That is, the imagined scenario remains tuned with how reality is. Second, our background knowledge has a causal role in our evaluation of the counterfactual. That is, when spontaneously developing the possible scenario in the light of our background knowledge, the way in which our imagination operates is reality-oriented. This is what makes imagination a reliable and predictive cognitive process. In fact, it is in virtue of its being constrained by previous experiences that the imagination is selective and truth-oriented, thereby "spontaneously" developing the possible scenarios in question. ${ }^{24,25}$ In the epistemology of counterfactuals, and in our imaginative exercises in general, sense experience thus plays an important role. As Williamson writes:

"[]]n our imagination-based knowledge of counterfactuals, sense experience can play a role that is neither strictly evidential nor merely enabling. For, even without serving as part of our total evidence, it can mold our habits of imagination and judgment in ways that go far beyond a merely enabling role." (Williamson, 2007: 165)

To sum up: given Williamson's cognitive-based account of imagination, sense experience plays an interesting epistemic role in imagination. Although not being strictly evidential, experience seems to play a role that is more than merely enabling one in understanding the concepts involved in the counterfactual. Given the less than strictly evidential yet more than merely enabling role that experience plays in the employment of our

\footnotetext{
23 Thanks to Aidan McGlynn for stressing this point.

${ }^{24} \mathrm{It}$ is important to point out that although imagination is reality-oriented, it is far from being an infallible way of gaining knowledge. Nonetheless, the reliability of this cognitive capacity is enough, on Williamson's view, to become of necessary use in our daily life, for example, as applied in our decision-making, or in the activity of mindreading, as well as in the way we gain knowledge about the future.

25 I believe that Goldman's simulation theory $(1989,2006)$ can offer a framework for a better understanding of Williamson's account of imagination. For instance, Goldman explicitly links imagination to simulation by defining the so-called enactment-imagination: "Enactment-Imagination is a matter of creating or trying to create in one's own mind a selected mental state, or at least a rough facsimile of such a state, through the faculty of imagination" (Goldman, 2006). However, I take our imaginative capacities to be something broader than what Goldman takes our simulative capacity to be. See also Gordon (1986) and Heal (1986) who were the first ones to propose simulation as an account of human psychology.
} 
imaginative capacities, and given the imagination-based epistemology of counterfactuals that Williamson defends, it follows that, on Williamson's view, knowledge of counterfactuals should not be classified as being a priori, nor a posteriori. The point can thus be generalised to any instance of knowledge involving our imaginative capacities. ${ }^{26}$ As a consequence, given that much of the knowledge traditionally thought of as a priori involves the employment of our imaginative capacities, it actually fails to fit within that category, for experience plays a role that is more than merely enabling. ${ }^{27}$ An example is provided in 'How Deep is The Distinction Between A Priori and A Posteriori Knowledge?', where Williamson considers the following two truths:
a.) All crimson things are red
b.) All recent volumes of Who's Who are red.

As Williamson points out, the standard view classifies one's knowledge of a.) as a priori knowledge, and one's knowledge of b.) as a posteriori knowledge. However, he argues that the cognitive process underlying one's knowledge that a.) and the cognitive process underlying one's knowledge that b.) are almost the same (Williamson, 2013). More precisely, he argues that what underlies one's knowledge in both cases is an imaginative process. As a consequence of his cognitive-based epistemology of imagination just described, Williamson argues that the experience plays a similar role both in one's knowledge of a.) as well as in one's knowledge of b.). On the standard view, one's knowledge of a.) relies on enabling experience only, thereby constituting a priori knowledge, while one's knowledge of b.) relies on evidential experience, thereby constituting an instance of a posteriori knowledge. Contra the standard view, Williamson argues that the role that experience plays, both in one's knowledge of a.) and in one's knowledge of b.), is “more than pure enabling and less than strictly evidential". On the one hand, in one's knowledge of a.), the experience of redness not only enables one to understand the proposition a.), it also provides one with the "skills in applying the terms 'crimson' and 'red' to the point

\footnotetext{
${ }^{26}$ For relevant discussion on the evidential-justificatory role of imagination see, for example, M. Balcerak Jackson (2016), (Forthcoming).

27 Williamson further claims that this shows that the a priori/a posteriori distinction lacks any relevant explanatory power. I do not want to commit myself to such a claim here.
} 
where he could carry out the imaginative exercise successfully". On the other hand, in one's knowledge of b.), the only role the experience plays is that it grounds "his skill in recognizing and imagining such volumes" (Williamson, 2013: 297).

In the previous section, I have reconstructed Williamson's account of imagination and how it is widely involved in different ways in our daily epistemic practices, e.g., in our evaluation of counterfactuals. I have pointed out how, on Williamson's view, imagination, broadly understood as one of our cognitive capacities, is sensitive to our past experiences: in our imaginative exercises, sense-experience plays a role which, although less than strictly evidential, is more than merely enabling.

Where does this leave us? In this section, I argue that Gary's knowledge of his evidence (and hence, his knowledge of his knowledge) involves the evaluation of counterfactual conditionals, and hence the employment of imaginative exercises. That is, first, I argue that we should understand second-order knowledge as partly entertaining and mentally visualising error-possibilities; second, I argue that, given the more-than-enabling role experience plays in the imagination, and given my imagination-based account of secondorder knowledge, Gary's knowledge of his knowledge does not represent an instance of armchair knowledge in a problematic sense. Given $\mathrm{E}=\mathrm{K}$, the same conclusion can be applied to Gary's knowledge of his evidence. Crucially, if this is so, the Armchair Access Problem does not represent a threat for $\mathrm{E}=\mathrm{K}$. Even if it is true that there is a sense in which Gary has "knowledge from the armchair" of what his evidence is, Gary's knowledge is not an instance of armchair knowledge as understood by Silins, and as underlying the Armchair Access thesis.

Remember that we are concerned here with a case of second-order knowledge in which Gary is a thoughtful subject. That is, Gary has second order knowledge that the dial reads 0.4 in virtue of the following two things: i) he has first-order knowledge that the dial reads 0.4 ; ii) he has conducted a further inquiry on his first-order knowledge. ${ }^{28}$ In the previous section, I have addressed the following two questions: first, what is the object of this further inquiry? Second, what is the nature of this inquiry? Providing an answer to the

\footnotetext{
${ }^{28} \mathrm{I}$ am here assuming failure of the KK-principle as originally defended by Hintikka (1962). Daniel Greco (2014) has recently offered a novel defense of the KK-principle. However, the vast majority of epistemologists would reject such a principle nowadays. In particular see Williamson (2000).
} 
first question will enable us to answer the second question, thereby shedding light on why Gary's first-order knowledge is empirical, yet his second-order knowledge is not an instance of armchair knowledge as intended by Silins.

In the scenario originally described, Gary knows that the dial reads 0.4 simply by looking at it. For Gary to conduct a further inquiry on his epistemic status means to check, without further empirical inquiry, whether he indeed had a knowledge-yielding visual experience. That is, Gary will consider whether the conditions for a paradigmatic good case of perceptual knowledge obtained. For example, he will consider whether his sight was good or not at the moment of the perceptual experience, whether the lights in the room were good, and so on. In a nutshell, for Gary to conduct a further inquiry on his epistemic status (in order to determine whether he had knowledge of a specific empirical proposition $\mathrm{p}$ ), is to conduct a further inquiry on whether his visual experience that $\mathrm{p}$ was a reliable one, thereby constituting a knowledge-yielding process.

It is important to stress that, as I mentioned above, this further inquiry must not involve any empirical check in the environment, yet it must be put forward merely "by reflection" alone. If this is so, then what, in practice, does it mean for Gary to conduct this further inquiry on the reliability of his visual experience? It means that Gary would probably consider the possibility of having had a non-reliable and non-paradigmatic visual experience. In practice, by addressing error-possibilities, Gary would consider what would be the case, if he had not had a paradigmatic visual experience. In addressing this possibility, he would appeal to his background knowledge and he would try to remember previous cases in which he had a visual experience of a dial, perhaps in the same room, or in a different room. He would then make a comparison between past experiences and the visual experience he has just undergone. That is, he would "make up his mind" on his epistemic situation without conducing any further empirical check. Gary's further inquiry would thus consist of addressing and evaluating counterfactual conditionals such as the following:

If I had not had a paradigmatic visual-experience of a dial reading 0.4, then it would not look like there was a dial reading $0.4^{29}$

${ }^{29}$ I am here ignoring any skeptical hypothesis. 
But, as I have said above, evaluating such a counterfactual involves considering errorpossibilities, mentally visualising past experiences and making comparisons with recent ones.

We can now go back to the second question I have addressed: what is the nature of this further inquiry? Given the above description of what Gary's second-order knowledge involves, I suggest we should understand Gary's inquiry on his epistemic status (required in order for him to have second-order knowledge) as involving the employment of those imaginative capacities that Williamson takes to be involved in our evaluating counterfactuals. In fact, as described in the above scenario, Gary seems to conduct this required inquiry by using much of the imaginative exercises that Williamson has taken to represent specific instances of the more general and heterogeneous cognitive capacity of transposing skills "offline". Crucially, I have pointed out that, according to Williamson, the employment of imaginative exercises is constrained by past experiences in such a way that makes imagination relying on more-than-enabling experience. It follows that Gary's secondorder knowledge involves cognitive capacities relying on experience that does not merely have an enabling role. Although Gary's past experience fails to have a strictly evidential role, it still constrains Gary's imaginative process in a significant way. But, if Gary's secondorder knowledge is not relying on merely enabling experience, then it is not an instance of armchair knowledge as understood by Silins. That is, it is not an instance of armchair knowledge in any problematic sense. Given $\mathrm{E}=\mathrm{K}$, the same can be said about Gary's knowledge that his evidence includes the proposition that the dial reads 0.4.

\section{3}

\section{WHY KNOWING THE ENVIRONMENT FROM THE}

\section{ARMCHAIR IS NOT ABSURD}

In the previous section, I have put forward a second line of response against Silins' Armchair Access Problem. I have questioned the main assumption underlying Silins' argument, namely, the Armchair Access thesis. I have argued that, although Gary's knowledge of his evidence is not empirical, it is not "armchair" in any problematic sense: Gary's inquiry on his epistemic situation is somehow constrained by experience, where this plays a quasi-evidential role. More precisely, along this second line of response, I have questioned the nature of Silins' notion of armchair knowledge as underlying the Armchair Access thesis. The Armchair Access Problem mistakenly relies on a picture according to 
which the enabling and the evidential role experience can play are mutually exclusive. There is, instead, a third role experience can play, one that is neither strictly evidential, nor merely enabling. I have argued that, once we take seriously Williamson's cognitive-based epistemology of imagination, and once we see how pervasive the employment of this cognitive capacity is, then we can think of a plausible imagination-based account of second-order knowledge (and, thus, of knowledge of one's evidence). What follows is that, even if there is a sense in which Gary has "armchair knowledge" of what his evidence is, Gary's knowledge of his evidence is based on this third quasi-evidential role of experience, thereby failing to bring about any disastrous conclusion. As Williamson says:

"[I]t should be no surprise if we turn out to have armchair knowledge of truths about the external environment." (Williamson, 2007: 269)

Before considering whether cases of "easy" second-order knowledge (i.e., cases that do not involve any inquiry) might affect my overall argument, let me make a final remark on a potentially interesting application of my imagination-based account of second-order knowledge. As mentioned earlier in this paper, the Armchair Access Problem is developed by Silins as a parallel to the McKinsey Paradox which establishes a tension between Content Externalism and Privilege Access. Now that we have a way of resisting the Armchair Access Problem, one might thus wonder whether a similar response is also available to the Content Externalist in order to escape the McKinsey Paradox. That is, perhaps the Content Externalist could accept that one can know by reflection contingent facts about the external environment, whilst arguing that this is not a problematic result, insofar as this 'reflective knowledge' is based on quasi-evidential experience. ${ }^{30}$ This potential line of response is one that deserves careful examination and that I have no time to address here. Nevertheless, I believe it is an option worth exploring in the future.

\footnotetext{
${ }^{30}$ For an interesting response to the McKinsey Paradox that accepts the conclusion of the paradox while arguing that it is not absurd see Sawyer (1998). See Maria Lasonen-Aarnio (2006) for an argument showing that a large class of McKinsey-style paradoxes are dialectically flawed. See also McKinsey's (2006) for McKinsey's response to Lasonen-Aarnio, and Lasonen-Aarnio (2008) for a response to McKinsey's response. For a useful survey of the various responses to the McKinsey Paradox see Kallestrup (2011, 2012: ch. 5).
} 


\section{EASY SECOND-ORDER KNOWLEDGE}

It could be objected that my account of second-order knowledge is not very plausible after all. One could argue, for instance, that no epistemic work is required for one to have second-order knowledge. According to this line of thought, my explanation of Gary's scenario would thus fail to show that Gary's knowledge of his evidence (and thus of his knowledge) is based on more than merely enabling experience. For, if Gary is able to gain second-order knowledge without engaging in counterfactual thinking, and without dismissing error-possibilities, then it seems Gary is not employing his imaginative capacities after all. But remember that my conclusion that Gary's second-order knowledge is grounded on quasi-evidential experience is a consequence of the fact that, as the story goes, it is plausible to take Gary as employing his imaginative capacities. The worry would thus be that, if second-order knowledge does not require a further epistemic inquiry, yet it comes "for free" together with first-order knowledge, then Silins seems right after all: Gary's knowledge is supposedly based on enabling experience only. In Section 4 of this paper, I have already noted that my account is compatible with the fact that there might be cases in which one can gain second-order knowledge easily by merely being exposed to one's first-order knowledge. Furthermore, I have pointed out that the cases Silins himself is interested in are cases in which the target subject is thoughtful, and in which he actively considers what evidence he has and what his evidence entails (Silins, 2005: 381). In this section, I argue that, even if one insisted that we should read Gary's second-order knowledge as not involving any inquiry, this interpretation of Gary's case would still fail to constitute a real threat to my response. First of all, if, as one might argue, one's secondorder knowledge comes almost "for free" together with one's first-order knowledge, then the following question arises: what is this second-order knowledge grounded on? One plausible answer could be that our second order-knowledge is rooted in the same epistemic basis our first-order knowledge is grounded on. However, if this turned out to be the most plausible account of second-order knowledge available, I would happily bite the bullet here, for it would basically concur with my conclusion that, contrary to what Silins claims, Gary's second-order knowledge is based on more than merely enabling experience. In fact, if this account of second-order knowledge is correct, we would have even a more direct response to Silins, given that Gary's second-order knowledge would turn out to be just as empirically 
based as his first-order knowledge is. ${ }^{31}$ A different way of answering my question could be to say that Gary's second-order knowledge does not require any further inquiry, and, at the same time, is not epistemically based on the same empirical ground on which Gary's firstorder knowledge is based. Crucially, defenders of this account owe us an explanation of where this second-order belief is gaining the justificatory support needed for this belief to constitute knowledge. Moreover, even if a plausible explanation is provided, I believe it would not affect my overall argument. On the one hand, all I wanted to argue for is that there is a plausible explanation of how we sometimes acquire knowledge of what our evidence is (and hence of our knowledge), one that sheds light on the role experience plays in these cases of second-order knowledge. It follows that, even if there can be cases in which one gains second-order knowledge without conducting any active inquiry on one's epistemic status, what matters is that this second-order knowledge is not based on merely enabling experience only. On the other hand, my account does not completely rule out cases of second-order knowledge that are genuine instances of "armchair knowledge" as intended by Silins. In fact, I take section 4 of this paper to show exactly this.

\section{CONCLUSION}

In this paper, I have considered Silins' Armchair Access Problem. This is supposed to represent a novel access argument against $\mathrm{E}=\mathrm{K}$, one which does not rely on a luminosity claim. The argument aims to show that $\mathrm{E}=\mathrm{K}$ is jointly incompatible with Armchair Access, i.e., the thesis that it is sometimes possible to know from the armchair what our evidence consists of. Williamson's $\mathrm{E}=\mathrm{K}$, together with Armchair Access, seems to lead to the disastrous conclusion that it is possible to have armchair knowledge of a specific empirical proposition. Given that Armchair Access is a very plausible claim, the argument (allegedly) represents a reductio ad absurdum of $\mathrm{E}=\mathrm{K}$.

This paper has rejected the Armchair Access Problem as a genuine problem for $\mathrm{E}=\mathrm{K} .{ }^{32}$ More precisely, I have put forward two lines of response. According to the first

\footnotetext{
31 One might also worry that the story I have provided, one that understands second-order knowledge as involving evaluation of counterfactual conditionals, is incompatible with Williamson's "knowledge-first" project. However, note that in The Philosophy of Philosophy Williamson extensively argues for his epistemology of counterfactuals within a knowledge-first framework. Here I am just applying that framework to cases of second-order knowledge.

32 Silins' paper has been very influential within the epistemological debate on Externalism and Internalism about evidence. However, most of the discussion that followed his Deception and Evidence mainly focused on his so-called 'Supervenience Argument' and his novel Sceptical Argument. For relevant discussion on these
} 
line of response, Silins' formulation of Armchair Access as an existential claim allows for a plausible restriction of Armchair Access to non-environmentally sensitive propositions. Williamson should thus reject the first premise of Silins' argument, thereby claiming that Gary does not have armchair knowledge that his evidence includes the proposition that the dial reads 0.4. According to the second line of response, everyone - including Williamson - should grant that there is a sense in which Gary can know "from the armchair" that his evidence includes the proposition that the dial reads 0.4. However, Gary's second-order knowledge is not an instance of armchair knowledge as underpinning Silins' Armchair Access Problem. In fact, the Armchair Access thesis as understood by Silins, relies on the assumption that experience can play either an enabling or an evidential role, where these roles are mutually exclusive. That is, Silins' formulation of Armchair Access overlooks the possibility of experience having a third role: one that is more than merely enabling and less than strictly evidential (what I have called quasi-evidential). Furthermore, I have offered an explanation of why I believe Gary's knowledge of what his evidence is (and thus, given $\mathrm{E}=\mathrm{K}$, knowledge of one's knowledge) represents an instance of knowledge based on quasi-evidential experience. More precisely, I have argued for a novel imagination-based account of second-order knowledge, one according to which we gain second-order knowledge by means of evaluating counterfactual conditionals, thereby employing our imaginative exercises. Crucially, if we take seriously Williamson's cognitivebased account of imagination, according to which imagination relies on more than merely enabling experience, then we are forced to rethink the role experience plays in secondorder knowledge. Second-order knowledge seems to rely on experience that, although less than strictly evidential, plays more than a mere enabling role.

Finally, let me highlight why these two lines of response are compatible and mutually supportive. If we understand "armchair knowledge" as knowledge based on enabling experience only - as Silins understands it - then Williamson should be happy to accept the Armchair Access thesis, while saying that one can only have armchair knowledge of non-environmentally sensitive propositions. It follows that Gary does not have armchair knowledge of the fact that his evidence includes the proposition that the dial reads 0.4.

arguments see Kennedy 2010, Dunn 2012, McGlynn 2014, and Fratantonio and McGlynn 2018. Less attention has been devoted to the Access Problem. Nevertheless, Littlejohn (2011) constitutes an exception. Note that my response differs from the one provided by Littlejohn for various reasons. In particular, while Littlejohn rejects any accessibility requirement motivating Armchair Access, this paper shows that it is in fact possible for the Externalist (or at least for the defender of $\mathrm{E}=\mathrm{K}$ ) to accommodate the intuition that we can often have knowledge merely "by reflection" of what our evidence consists of. 
This is what the first line of response has shown. At the same time, Williamson could grant that there is a sense in which Gary has knowledge "from the armchair" of what his evidence is, while rejecting the idea that Gary has armchair knowledge (as defined by Silins) of the target proposition. The conclusion (3) that Gary knows merely "from the armchair" the specific empirical proposition that the dial reads 0.4 thus follows from the premises (1) and (2). However, this does not represent a disastrous consequence, for Gary's knowledge is based on more than mere enabling experience. This is what the second line of response has shown. The moral of the story is that the Armchair Access Problem rests on an ambiguity over the notion of armchair knowledge underpinning its main assumption (i.e., Armchair Access thesis). Once we get clear on which notion of armchair knowledge we are considering, we realise that the Armchair Access Problem does not represent a serious challenge for $\mathrm{E}=\mathrm{K}$.

\section{REFERENCES}

Balcerak Jackson, M. 2018. Justification by Imagination. in F. Macpherson \& F. Dorsch (Eds.) Perceptual Memory and Perceptual Imagination. Oxford: Oxford University Press.

----- (2016). On the Epistemic Value of Imagining, Supposing, and Conceiving. In A. Kind \& P. Kung (Eds.) Knowledge Through Imagination. Oxford: Oxford University Press.

Brown, J. (2004). Anti-Individualism and Knowledge. Cambridge, Mass.: MIT Press.

Dunn, J. (2012). 'Evidential Externalism', Philosophical Studies 158 (3):435-455 Farkas, K. (2008). The Subject's Point of View. Oxford: Oxford University Press.

Fratantonio, G. and McGlynn, A. 2018. 'Reassessing The Case Against Evidential Externalism', in Veli Mitova (ed.), The Factive Turn in Epistemology, Cambridge University Press, pp. 84-101.

Fratantonio, G. forthcoming. 'Evidential Internalism and Evidential Externalism', in The Routledge Handbook for the Philosophy of Evidence, Routledge.

Goldman, A. (1989), 'Interpretation Psychologized', in Mind and Language, 4: 161- 185; reprinted in M. Davies and T. Stone (eds.), Folk Psychology: The Theory of Mind Debate, Oxford: Blackwell Publishers, 1995

----- (2006). Simulating Minds: The Philosophy, Psychology, and Neuroscience of Mindreading,

Oxford: Oxford University Press.

Gordon, R. (1986). 'Folk Psychology as Simulation', in Mind and Language, 1: 158- 171; reprinted in M. Davies and T. Stone (eds.), Folk Psychology: The Theory of Mind Debate, Oxford: Blackwell Publishers, 1995. 
Greco, D. (2014) 'Could KK be OK?', Journal of Philosophy. 111 (4):169-197.

Heal, J. (1986) 'Replication and Functionalism', in Language, Mind, and Logic, J. Butterfield (ed.), Cambridge: Cambridge University Press; reprinted in M. Davies and T. Stone (eds.), Folk Psychology: The Theory of Mind Debate, Oxford: Blackwell

Publishers, 1995

Hintikka, J. (1962). Knowledge and Belief. Ithaca, N.Y.: Cornell University Press.

Kallestrup, J. (2012). Semantic Externalism. Oxon: Routledge.

Kallestrup, J. (2011). 'Recent Work on McKinsey's Paradox', Analysis 71 (1):157-171

Kennedy, M. (2010). Naïve Realism and Experiential Evidence. Proceedings of the Aristotelian Society , 110, 77-109.

Lasonen-Aarnio, M. (2008). 'Why the Externalist is Better Off Without Free Logic: A reply to McKinsey', in Dialectica 62 (4): 535-540.

----- (2006). 'Externalism and A Priori Knowledge of The World: Why Privileged Access is Not the Issue', in Dialectica 60 (4): 433-445.

Lawson-Tancred, H., 1986, Aristotle: De Anima, Harmondsworth: Penguin. Littlejohn, C. (2012). Justification and the Truth-Connection. Cambridge: Cambridge University Press.

Littlejohn, C. (2011). 'Evidence and Amrchair Access', in Synthese 179 (3):479-500

Logins, A. (2016). 'Necessary truths, evidence, and knowledge', in Unisinos Journal of Philosophy 17(3): 302-307.

McCain, K. (2012). Evidentialism and Epistemic Justification, in Routledge Studies in Contemporary Philosophy.

McGlynn, A. (2014). Knowledge First? Basingstoke: Palgrave Macmillan.

McKinsey, M. (2006). 'Direct Reference and Logical Truth: A reply to Lasonen-Aarnio', in Dialectica 60 (4): 447-451.

----- (1991). 'Anti-Individualism and Privileged Access'. Analysis , 51, 9-

16.

Nuccetelli, S. (1999). 'What Anti-Individualists Cannot Know A Priori'. Analysis, 59, 4851.

Pritchard, D. (2012). Epistemological Disjunctivism. Oxford: Oxford University Press. 
---- (2011). 'Evidentialism, Internalism, Disjunctivism', In T. Dougherty (Ed.), Evidentialism and its Discontents (pp. 235-53). Oxford: Oxford University Press.

Sawyer, S. (1998). 'Privileged Access To The World', Australasian Journal of

Philosophy 76 (4):523-533

Silins, N. (2005). 'Deception and Evidence', Philosophical Perspectives , 19, 375-404.

Smith, M. (2916). Between Probability and Certainty, Oxford: Oxford University Press.

Williamson, T. (2016) 'Knowing by Imagining', in A. Kind \& P. Kung (Eds.) Knowledge Through Imagination. Oxford: Oxford University Press.

----- (2013) 'How deep is the distinction between A Priori and A Posteriori Knowledge', in A. Casullo \& J. C. Thurow (Eds.), The A Priori in Philosophy. Oxford University Press. pp. 291-312

----- (2007). The Philosophy of Philosophy. Oxford: Blackwell Publishing.

----- (2000). Knowledge and its Limits. Oxford: Oxford University Press. 